\title{
Anode Properties of Lithium Storage Alloy Electrodes Prepared by Gas-Deposition
}

\author{
Hiroki Sakaguchi, ${ }^{\mathrm{Z}}$ Takafumi Toda, Yoshitaka Nagao, and Takao Esaka* \\ Department of Materials Science, Faculty of Engineering, Tottori University, 4-101 Minami, Koyama-cho,
} Tottori 680-8552, Japan

To improve the charge-discharge cycle stability, we adopted a gas-deposition (GD) method to prepare lithium storage alloy electrodes. The resulting $\mathrm{Mg}_{2} \mathrm{Ge}$ GD film exhibited an increase in both charge and discharge capacities in comparison with the conventional bulk electrode, suggesting improvement of adhesion between the $\mathrm{Mg}_{2} \mathrm{Ge}$ layer and $\mathrm{Cu}$ foil. Furthermore, the cyclability of the GD film electrode was noticeably superior to that of the bulk electrode. The discharge capacity of the film electrode maintained $35 \%$ of the initial capacity, even at the 200th cycle. It is noteworthy that the GD-film electrode was able to operate at very large current densities.

(C) 2007 The Electrochemical Society. [DOI: 10.1149/1.2772409] All rights reserved.

Manuscript submitted April 17, 2007; revised manuscript received July 18, 2007. Available electronically August $31,2007$.

Alloys containing elements from 14 family groups are prospective negative-electrode materials for second-generation rechargeable lithium batteries, replacing carbon materials. ${ }^{1-13}$ To date we have focused our research on $\mathrm{Mg}_{2} \mathrm{Ge}$ and found that the charge-discharge capacity of its composing electrodes is higher than that of carbon materials and that its electrochemical reaction is largely based on the reversible absorption and desorption of lithium in the crystal lattice. ${ }^{14-17}$ However, the typical problem of alloy electrodes, namely, low stability of the charge-discharge cycle, exists also for this compound. We believe this problem does not originate in the properties of the compound material itself, and that it is resolvable by elaboration of the production method of the electrode. In order to achieve this, a method whereby a strong adhesion can be created between the particles of the active material, as well as between the particles and the electron collector, is desirable.

Although physical vapor deposition, such as vacuum evaporation ${ }^{18}$ and sputtering, ${ }^{19}$ or plating ${ }^{13,20,21}$ can be considered the usual film-forming methods suitable for such a purpose, in the present research we have concentrated on a gas-deposition (GD) method (also referred to as an aerosol deposition method) whereby the raw material powder placed in a guide tube is turned into aerosol by feeding it into an evacuated chamber together with argon gas, and a film is created by projecting it through a nozzle on the substrate at high speed, in the range of the speed of sound. This method is expected to confer various advantages, including $(i)$ the production of electrodes exhibiting a strong adhesion between the particles of the active material as well as between the particles and the electron collector, $(\mathrm{ii})$ the ability to prepare a film while maintaining the material composition due to the lack of heat-induced decomposition, and (iii) ease of preparation of a thick film. Although this method has been applied to the preparation of a thick film of piezoelectric material, ${ }^{22,23}$ it is thought that the present research pioneers the application to the preparation of electrodes for rechargeable batteries. $^{24,25}$

Using this technique, electrodes were produced by applying $\mathrm{Mg}_{2} \mathrm{Ge}$ on a copper foil, and the results from evaluating the anode properties, with special emphasis on the cycle life and the high-rate charge-discharge properties, are reported herein.

\section{Experimental}

In the preparation of $\mathrm{Mg}_{2} \mathrm{Ge}$ film electrodes using the GD method, $\mathrm{Mg}_{2} \mathrm{Ge}$ powder synthesized by mechanical alloying was used as the raw material. ${ }^{14-16}$ The size of the material particles was 0.5-3 $\mu \mathrm{m}$. A $20 \mu \mathrm{m}$ thick film of $\mathrm{Mg}_{2}$ Ge was applied on a $\mathrm{Cu}$ foil substrate. As for the conditions for forming the film, the initial pressure of the carrier gas argon was set in the interval between 2 and

\footnotetext{
* Electrochemical Society Active Member.

${ }^{\mathrm{z}}$ E-mail: sakaguch@chem.tottori-u.ac.jp
}

$8 \times 10^{5} \mathrm{~Pa}$, the radius of the injection nozzle was set to $\phi 0.8$ or 1.0 , and the distance between the nozzle and the substrate was set to $10 \mathrm{~mm}$. Furthermore, the chamber where the substrate was placed was evacuated in advance. The material used for one injection (having the same meaning as deposition) was about $20 \mathrm{mg}$. In the present research, apart from one-time injection, a sample formed by repeatedly injecting the raw material three times on the same spot of the substrate was also prepared.

Compound phase identification, distribution of the elements, and composition analysis were investigated for the obtained alloy films using an X-ray diffractometer (XRD) for thin film, energydispersive X-ray (EDX) analysis, and inductively coupled plasma (ICP). Furthermore, the surface was observed using scanning electron microscopy (SEM) and scanning ion microscopy (SIM).

For the charge-discharge experiment, a beaker-type three-

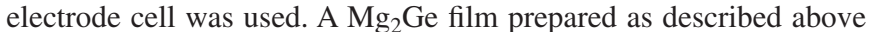
was applied to the tested electrode, lithium was used for the counter and reference electrodes, and $1 \mathrm{M} \mathrm{LiClO}_{4}$ /propylene carbonate (PC) was used as electrolyte. The current density for the measurement was set to $1.0,2.5$, or $3.3 \mathrm{~A} \mathrm{~g}\left(\mathrm{Mg}_{2} \mathrm{Ge}\right)^{-1}$, and the potential range was set to $0.005-2.0 \mathrm{~V}$ for the potential of the reference electrode.

Our conventional electrode was prepared by interleaving the raw material powder into a copper mesh $\left(100\right.$ mesh, $\left.0.21 \mathrm{~mm}^{2}\right)$ and bonding them by applying pressure of $200 \mathrm{kgf} \mathrm{cm}^{-2}$. For the purposes of comparison with the present research, the properties of the electrodes manufactured using the ordinary technique are discussed below and are referred to hereafter for the sake of convenience as bulk electrode.

\section{Results and Discussion}

The $\mathrm{Mg}_{2} \mathrm{Ge}$ GD films on a copper foil prepared by variously altering the nozzle radius, the pressure of the carrier gas, and the pressure inside the chamber are shown in the photographs in Fig. 1. With regard to film-forming conditions, it was established that the largest amount of adhered active material and a film of excellent adhesiveness with respect to the copper foil was achieved for a nozzle radius of $0.8 \mathrm{~mm}$ and differential pressure of $7 \times 10^{5} \mathrm{~Pa}$. This film was attached so well to the copper foil that it could not be removed easily, even by scrubbing with a metal spatula.

Next, as shown in Fig. 2, compound phase identification for the obtained film was conducted by using an X-ray diffractometer for thin film. $\theta$ in the figure represents the incidence angle of the $\mathrm{X}$-rays with respect to the film. For any incidence angle, a consistent pattern attributable to the cubic $\mathrm{Mg}_{2} \mathrm{Ge}$ phase is observed, and it was established that the film with a homogeneous structure can be obtained by the GD method.

It is realized from the SEM image of the surface of the $\mathrm{Mg}_{2} \mathrm{Ge}$ GD film shown in Fig. 3 that the configuration of the surface of the $\mathrm{Mg}_{2} \mathrm{Ge}$ film obtained by the GD method does not form a densely continuous film but rather that it is composed of fine particles 
Differential pressure [ Carrier gas - Inside the chamber ]
$3 \times 10^{5} \mathrm{~Pa}$
$5 \times 10^{5} \mathrm{~Pa}$
$7 \times 10^{5} \mathrm{~Pa}$
$9 \times 10^{5} \mathrm{~Pa}$

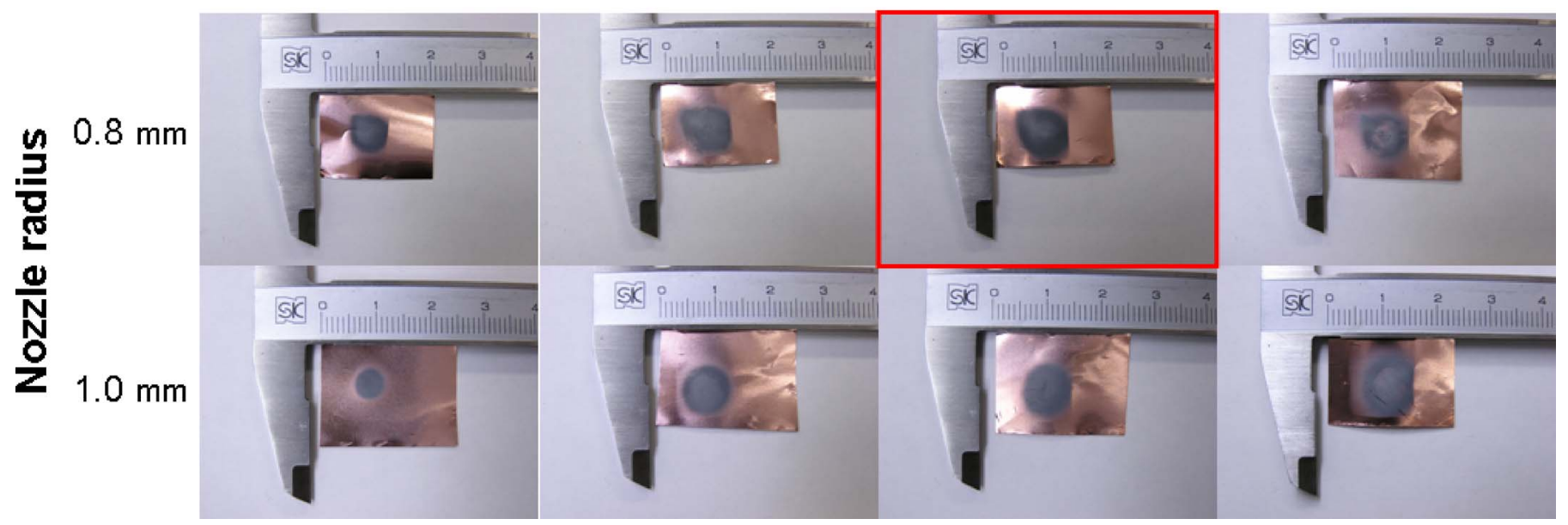

Figure 1. (Color online) Photographs of $\mathrm{Mg}_{2} \mathrm{Ge}$ GD films on a copper foil.

pressed together. A remarkable crack was not observed in the electrode obtained after cycling, though the surface of electrode had roughened due to expansion and contraction.

Furthermore, looking at the EDX element mapping image, it is realized that both magnesium and germanium are evenly distributed on the surface of the film. Moreover, the composition of the pres-

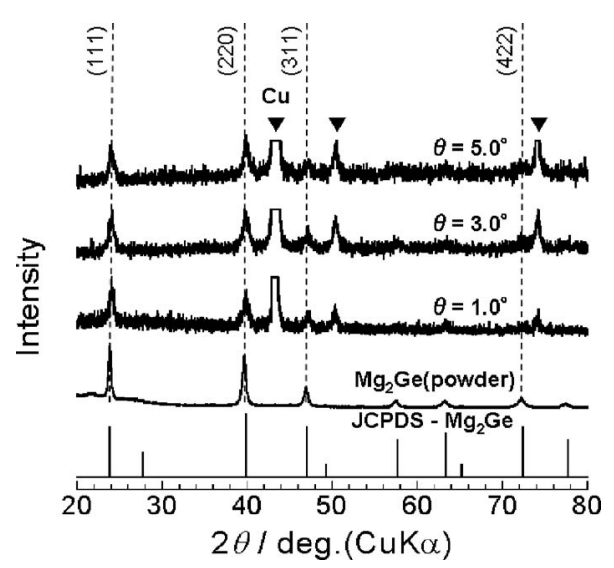

Figure 2. XRD patterns of $\mathrm{Mg}_{2} \mathrm{Ge}$ GD films.

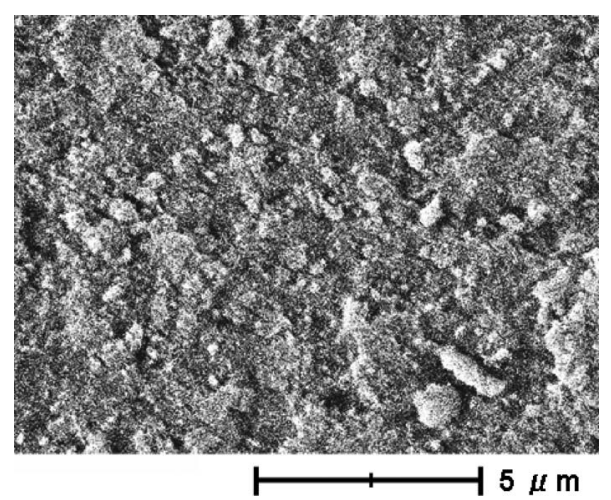

Figure 3. SEM image of the surface of a $\mathrm{Mg}_{2} \mathrm{Ge}$ GD film. GD conditions: nozzle radius $\phi 0.8$ and differential pressure $7 \times 10^{5} \mathrm{~Pa}$. ently obtained thick film was $\mathrm{Mg}_{2.07} \mathrm{Ge}$, and as projected, no compositional discrepancies from the raw material powder could be confirmed.

Figure 4 shows the charge-discharge curves of the first cycle for $\mathrm{Mg}_{2} \mathrm{Ge}$ GD-film electrodes with different film thicknesses, being ca. 3 and $7 \mu \mathrm{m}$. Because the charge-discharge profiles and the chargedischarge capacity reversibility of the GD-film electrodes closely matched those of the bulk electrode, it was decided that there was no difference in the electrode reaction for the two. However, the fact that both charge and discharge capacities were obviously larger for the GD-film electrodes strongly suggests that the electron collectivity had increased. Also, because the mass of the active material increased for the electrode with a thicker layer, due to equipment limitations, while the current density decreased by $0.5 \mathrm{~A} \mathrm{~g}^{-1}$, it was established that there was virtually no decrease in the chargedischarge capacity in comparison with the thinner film electrode.

The changes in the discharge capacity retention following the increase in the number of cycles of the electrodes are shown in Fig. 5. In contrast with the conventional bulk electrode that dies after numerous cycles, the GD-film electrodes, despite their capacity being reduced with the initiation of the cycles, maintained a discharge capacity of about $35 \%$ of the initial cycle even after 200 cycles, thus displaying a significant improvement of the cycle life performance.

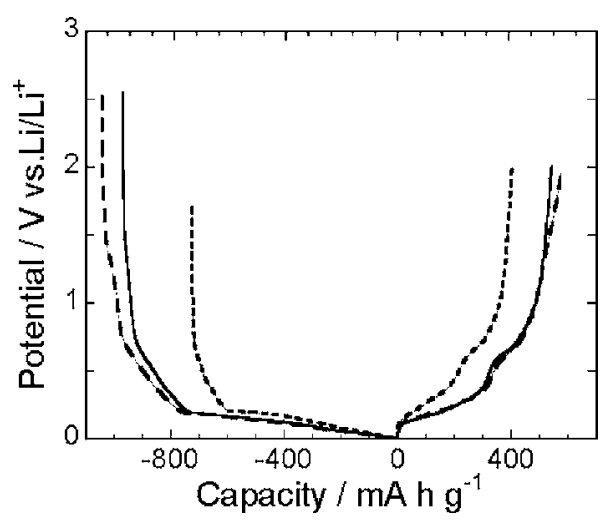

Figure 4. Charge-discharge curves of $\mathrm{Mg}_{2} \mathrm{Ge}$ GD-film electrodes: (-) three-times injection, (- - ) one-time injection, and (.....) bulk electrode. GD condition: nozzle radius $\phi 0.8$ and differential pressure $7 \times 10^{5} \mathrm{~Pa}$. 


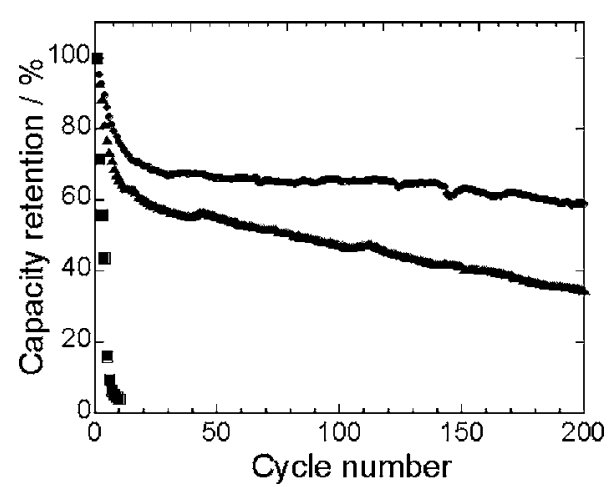

Figure 5. Cycle life performance of $\mathrm{Mg}_{2} \mathrm{Ge}$ GD-film electrodes: (O) threetimes injection, $(\boldsymbol{\Delta})$ one-time injection, and ( $\boldsymbol{\square})$ bulk electrode. GD condition: nozzle radius $\phi 0.8$ and differential pressure $7 \times 10^{5} \mathrm{~Pa}$.

Moreover, it became clear that the stability of the cycle was not reduced by increasing the thickness of the active material layer. In the galvanostat used in the present study, the minimum value of a current which can be thrown was $0.1 \mathrm{~mA}$. The measurements were carried out at the minimum current density, so that a current density was smaller for the thicker film electrode than the thinner one. Thus, the reason the thicker film showed longer cycle life than the thinner film appears to be the decrease in current density. Obtaining such favorable charge-discharge cycle characteristics even for electrodes with thickened film means that the way forward for developing batteries with alloy film electrodes possessing practical energy density is now clear.

Figure 6 shows the charge-discharge curves for the first cycle when the current density was changed with respect to the GD-film electrodes. Although the charge-discharge capacity gradually decreases as the current density becomes larger, because the current density of any of those electrodes far surpasses the current density of the bulk electrode, the aforementioned electrodes displayed a strong potential for application as high-rate charge-discharge electrodes, and there are good prospects for the invention of batteries having high power density.

The reasons for the remarkable improvements in the $\mathrm{Mg}_{2} \mathrm{Ge}$ electrodes in comparison with the bulk electrode are discussed below. Figure 7 is a SIM image of the cross section of the $\mathrm{Mg}_{2} \mathrm{Ge}$ GD film obtained through focused ion beam (FIB) processing. Using $\mathrm{GD}$, the $\mathrm{Mg}_{2} \mathrm{Ge}$ particles collide with the copper foil substrate and penetrate deeply into the substrate, thus becoming fixed in place. Furthermore, adhesiveness is increased because the individual par-

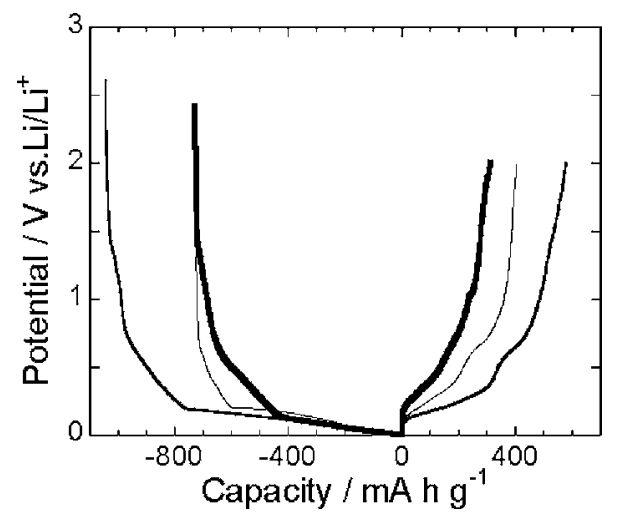

Figure 6. High-rate charge-discharge characteristics of $\mathrm{Mg}_{2} \mathrm{Ge}$ GD-film electrodes ( $(-)$ at $3.3 \mathrm{~A} \mathrm{~g} \mathrm{~g}^{-1},(-)$ at $1.0 \mathrm{~A} \mathrm{~g}^{-1}$, and (-) bulk electrode at $0.02 \mathrm{~A} \mathrm{~g}^{-1}$. GD condition: nozzle radius $\phi 0.8$ and differential pressure $7 \times 10^{5} \mathrm{~Pa}$.

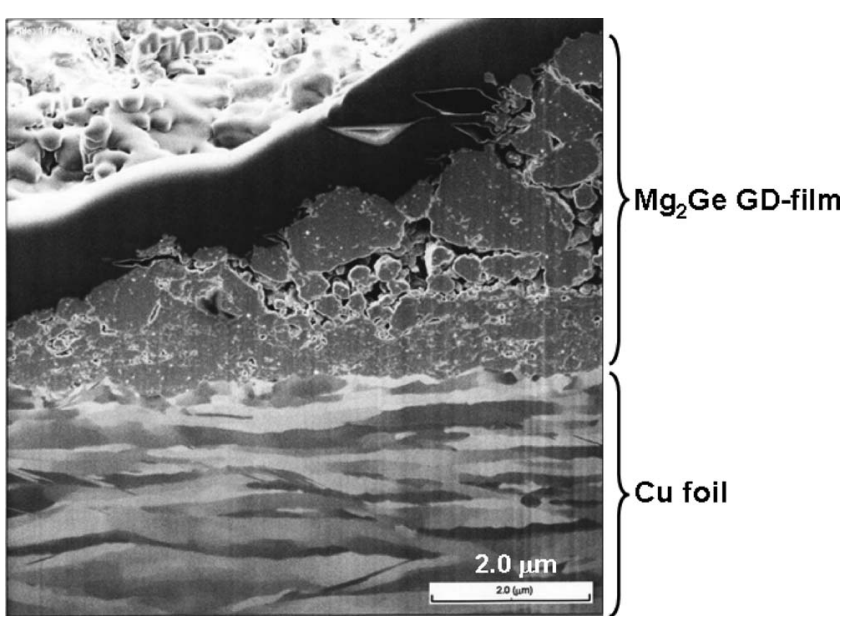

Figure 7. SIM image of the cross section of $\mathrm{Mg}_{2} \mathrm{Ge}$ GD film. GD condition: nozzle radius $\phi 0.8$ and differential pressure $7 \times 10^{5} \mathrm{~Pa}$.

ticles also collide with each other and plastically change shape. Places where the grain boundary can be considered lost can also be seen. At the same time, voids were confirmed to exist in various places in the film, possibly relieving the stress produced by the changing volume of the particles of the active material when charging or discharging. It is considered that the result of the synergetic effects is that electrically independent states do not emerge even if the layers of active material expand or contract during charge or discharge, improving the cycle life performance.

\section{Conclusion}

Thick $\mathrm{Mg}_{2} \mathrm{Ge}$ film electrodes having homogeneous structure and composition were produced by employing the GD method. The GDfilm electrodes surpassed the charge-discharge capacity and displayed notably superior cycle life in comparison to the bulk electrode. Significant improvement in the high-rate charge-discharge performance was confirmed for the GD-film electrodes.

\section{Acknowledgments}

This work has been partially supported by a Grant-in-Aid for Scientific Research from the Ministry of Education, Science, Sports and Culture of Japan.

Tottori University assisted in meeting the publication costs of this article.

\section{References}

1. O. Mao, R. A. Dunlap, and J. R. Dahn, J. Electrochem. Soc., 146, 405 (1999)

2. K. D. Kepler, J. T. Vaughey, and M. M. Thackeray, Electrochem. Solid-State Lett., 2, 307 (1999).

3. J. Yang, Y. Takeda, N. Imanishi, J. Y. Xie, and O. Yamamoto, Solid State Ionics, 133, 189 (2000).

4. H. Sakaguchi, H. Maeta, M. Kubota, H. Honda, and T. Esaka, Electrochemistry (Tokyo, Jpn.), 68, 632 (2000).

5. H. Honda, H. Sakaguchi, T. Fukunaga, and T. Esaka, Electrochemistry (Tokyo, Jpn.), 70, 99 (2002).

6. H. Honda, H. Sakaguchi, Y. Fukuda, and T. Esaka, Mater. Res. Bull., 38, 647 (2003).

7. H. Sakaguchi, H. Honda, Y. Akasaka, and T. Esaka, J. Power Sources, 119-121, 50 (2003).

8. H. Honda, H. Sakaguchi, I. Tanaka, and T. Esaka, J. Power Sources, 123, 216 (2003)

9. J. Yin, M. Wada, S. Tanase, and T. Sakai, J. Electrochem. Soc., 151, A867 (2004).

10. L. Wang, S. Kitamura, K. Obata, S. Tanase, and T. Sakai, J. Power Sources, 141, 286 (2005)

11. S. Matsuno, T. Kohno, N. Takami, F. Kawashima, and T. Sawa, Electrochem Solid-State Lett., 8, A234 (2005)

12. H. Mukaibo, T. Momma, and T. Osaka, J. Power Sources, 146, 457 (2005).

13. N. Tamura, Y. Kato, A. Mikami, M. Kamino, S. Matsuta, and S. Fujitani, J. Electrochem. Soc., 153, Al626 (2006).

14. H. Sakaguchi, H. Honda, and T. Esaka, Denki Kagaku oyobi Kogyo Butsuri Kagaku, 66, 1291 (1998).

15. H. Sakaguchi, H. Honda, and T. Esaka, J. Power Sources, 81-82, 229 (1999).

16. H. Sakaguchi, H. Honda, H. Maeta, and T. Esaka, The Japan Institute of Metals, 
Proceedings, Vol. 12, p. 1305 (1999).

17. H. Honda, H. Sakaguchi, T. Fukunaga, and T. Esaka, Electrochemistry (Tokyo, Jpn.), 70, 99 (2002).

18. H. Sakaguchi, T. Toda, and T. Esaka, Electrochemistry (Tokyo, Jpn.), 73, 505 (2005).

19. K.-I. Lee, J.-Y. Jung, S.-W. Lee, H.-S. Moon, and J.-W. Park, J. Power Sources, 129, $270(2004)$

20. L. Wang, S. Kitamura, K. Obata, S. Tanase, and T. Sakai, J. Power Sources, 141, 286 (2005).
21. H. Morimoto, S. Tobishima, and H. Negishi, J. Power Sources, 146, 469 (2005).

22. S. Kashu, E. Fuchita, T. Manae, and C. Hayashi, Jpn. J. Appl. Phys., Part 2, 23, L910 (1984).

23. J. Akedo and M. Lebedev, Jpn. J. Appl. Phys., Part 1, 38, 5397 (1999).

24. H. Sakaguchi, T. Toda, A. Seta, and T. Esaka, Abstracts of the 71st Meeting of The Electrochemical Society of Japan, p. 1J26 (2005).

25. H. Sakaguchi, T. Toda, A. Seta, and T. Esaka, Abstracts of the International Meeting on Lithium Batteries (IMLB2006), Paper no. 265 (2006). 